\title{
LOS MICRORRELATOS FANTÁSTICOS DE RAMÓN GÓMEZ DE LA SERNA
}

\author{
DARÍO HERNÁNDEZ ${ }^{1}$
}

Universidad de La Laguna

\begin{abstract}
Resumen
Ramón Gómez de la Serna dedicó una parte importante de su producción literaria a la composición de microrrelatos. Muchos de estos microrrelatos se pueden clasificar temáticamente como fantásticos. Los tres factores principales que condujeron al escritor madrileño a emplear la fantasía en ellos fueron: una nueva manera de observar y describir la realidad, sus ansias de transgresión estética y su deseo de atomizar sus relatos.
\end{abstract}

Palabras clave: Ramón Gómez de la Serna, microrrelatos, fantasía, realidad, transgresión.

\begin{abstract}
Ramón Gómez de la Serna dedicated a significant portion of his literary work to the composition of short-short stories. Many of these can be classified thematically as fantastical short-short stories. The three main factors that led to the Spanish writer to employ the fantasy in them were: a new way of observing and describing reality, his desire for aesthetic transgression and his wish to cut down his stories.
\end{abstract} Key words: Ramón Gómez de la Serna, short-short stories, fantasy, reality, transgression.

Teniendo en cuenta que son múltiples las teorías existentes sobre el fenómeno de la fantasía en la literatura, conviene que precisemos de entrada nuestra posición al respecto, la cual coincide en líneas generales con la mantenida por David Roas, experto conocedor del asunto, como demuestra, entre otras de sus obras, su ensayo titulado " $\mathrm{La}$ amenaza de lo fantástico". A grandes rasgos, podemos decir que lo que caracteriza la literatura fantástica y la diferencia de la realista es la ineludible inclusión en sus obras de un elemento sobrenatural, "y lo sobrenatural es aquello que transgrede las leyes que organizan el mundo real, aquello que no es explicable, que no existe, según dichas leyes" (Roas, 2001: 8). Entre el realismo y la fantasía se encontrarían otras vertientes con características propias, como la literatura maravillosa, en la que "lo sobrenatural es mostrado como natural" (Roas, 2001: 10) -ejemplos serían los relatos de hadas o los de ciencia-ficción- o el también conocido realismo mágico o maravilloso, en el que lo sobrenatural y lo cotidiano se entremezclan sin causar fractura, "lo que implica -y de ahí surge el término 'realismo maravilloso' —un modo de expresión realista" y da lugar a "una forma híbrida entre lo fantástico y lo maravilloso" (Roas, 2001: 12-13).

\footnotetext{
${ }^{1}$ Universidad de La Laguna. Correo: darher@ull.es. Recibido: 01-12-2015. Aceptado: 21-07-2015.
} 
Tres son los factores más importantes que, desde nuestro punto de vista, influyeron en Ramón Gómez de la Serna a la hora de elegir la fantasía como cauce expresivo de gran parte de su producción de microrrelatos: su particular visión de la realidad, sus ansias de transgresión estética y su propósito de aumentar el grado de concisión de sus textos, ya que una de "las vías más productivas para ahorrar espacio textual es la que explora los motivos y formas de lo fantástico" (Andres-Suárez, 2010: 104).

El escritor madrileño comenzó su creación literaria partiendo de un cambio de óptica, luego representado simbólicamente con su ingenioso "monóculo sin cristal". En su breve monólogo conocido como "El orador"2, Gómez de la Serna (1928) explicaba lo siguiente: "No consiste más que en un monóculo sin cristal. Monóculo sin cristal con el cual yo veo las cosas de relieve anotando todo lo que tienen de extraordinario. [...] Todas estas observaciones de la realidad, unidas a mi monóculo sin cristal, dan la base sincera de mi estética".

Ciertamente, esta estética personal de la que hablaba el madrileño estaba fundamentada, entre otras cosas, en su oposición al realismo literario decimonónico, pero no al realismo en un sentido amplio del concepto, es decir, entendido como un método de observación y transmisión de la realidad que permitiría al escritor percibir hasta lo más insignificante, traspasar el marco de lo apreciable a simple vista para penetrar en lo recóndito, convertir lo trivial en trascendente y establecer así conexiones inauditas entre las cosas. En este sentido, quizá convendría más relacionar la obra de Gómez de la Serna con la idea de 'hiperrealismo', defendida por David Roas, que con la de 'antirrealismo', aplicada por Antonio Rivas al análisis de la producción literaria del madrileño ${ }^{3}$, pues el elemento sobrenatural que define a la literatura fantástica a menudo

\footnotetext{
${ }^{2}$ Monólogo del madrileño filmado en 1928 y sobre el que Román Gubern (1997: 350) aporta importante información: "A continuación se proyectó un monólogo de tres minutos y medio de Ramón Gómez de la Serna que, a falta de rótulos iniciales, los programadores del Cineclub y la historiografía cinematográfica española han dado el título de 'El orador', aunque también se le designa a veces como 'El orador bluff' -así se citó en el artículo 'Historia del Cineclub Español' de La Gaceta Literaria- y 'La mano'. Fue rodado en Madrid por el burgalés Feliciano Vitores en el primer semestre de 1928, con el rudimentario sistema sonoro Phonofilm, que el ingeniero e inventor norteamericano Lee de Forest intentó implantar en España. [...] Este monólogo filmado de Ramón, en un sólo plano medio frontal y estático y al aire libre, tiene el aspecto de una tardía experiencia paradadaísta. En ella Ramón, como un gran prestidigitador de la palabra, manipula un par de monóculos y una gran mano postiza, prótesis grotesca que utilizó también en varias conferencias pronunciadas en aquella época. [...] El monólogo de Ramón se inicia cuando Ramón saca del bolsillo superior de su chaleco un monóculo y lo blande para exhibirlo". Este monólogo, no obstante, es posterior a la publicación de su artículo titulado "El monóculo sin cristal", que apareció en Nuevo Mundo el 14 de diciembre de 1923.
}

\footnotetext{
${ }^{3}$ Antonio Rivas entiende el empleo de la fantasía por parte de Gómez de la Serna como uno de los resultados derivados de lo que sería su general 'poética antirrealista': "La estructura deslavazada de la trama, la brevedad, en ocasiones extrema, la ruptura del encadenamiento lógico-causal o la configuración del relato como la irrupción súbita de un hecho sorprendente se corresponden con la decidida destrucción de la mímesis. Tal característica se encuentra tanto en la base de la narrativa 'larga' de Ramón Gómez de la Serna cuanto en la pulsión creativa que anima sus microrrelatos" (Rivas, 2009: 136). Mayor conexión con nuestros planteamientos tiene, como decimos, la propuesta de David Roas, cuyo concepto de 'hiperrealismo' puede ser muy útil al estudiar los relatos fantásticos de Gómez de la Serna: "Podríamos plantear lo fantástico como una especie de 'hiperrealismo', puesto que, además de reproducir las técnicas de los textos realistas, obliga al lector a confrontar continuamente su experiencia de
} 
parece emerger en los relatos ramonianos de la propia realidad y no de escenarios externos a esta, es decir, que se presenta como fruto de una penetrante visión del autor en la realidad misma que permite desvelar sus secretos, o sea, lo existente oculto, pero que, precisamente por no formar parte de lo aparente o lo cotidiano, se interpreta como sobrenatural. Sobre este hecho reflexionó en varias ocasiones el propio Gómez de la Serna, como muestra Ioana Zlotescu (1997: 29), quien pone como ejemplo de ello algunos de los pasajes de Pombo (1918) y La sagrada Cripta de Pombo (1924):

Lo insólito que se puede encontrar en la obra ramoniana nace de un realismo básico, microscópico, de 'lupa' como afirmaba Ortega, sin selección jerárquica. A pesar de declarar primero que "nuestra estética es 'pombiana' " [...] Nada más [...] Nuestra estética es un secreto", unas páginas más adelante, en el párrafo titulado "Yo", del mismo libro Pombo, confiesa Ramón: "...soy solo una mirada ancha, ancha como toda mi cara [...] ni soy escritor, ni un pensador, ni nada. Yo solo soy, por decirlo así, un mirador, y en esto creo que está la única facultad verdadera [...] algo que es solo la facultad de que entre la realidad en nosotros, pero no como algo que retener o agravar, sino como un puro objeto de tránsito". Y en La Sagrada Cripta de Pombo, en el párrafo "Estética" de "Mi autobiografía", continúa afirmando que "sometido a la realidad más perentoria", intenta "algo que sea fantástico, matizado de estilo. Que no sea tan aburrido y tan chabacano y tan de piedra como el otro realismo, ni tan soporífero como lo imaginativo" (las cursivas son mías). Este otro realismo, que se opone al realismo de raíces decimonónicas, es la gran impronta del arte ramoniano, que lo hace ser tan moderno.

Eco de estas reflexiones del madrileño se hicieron críticos de su obra como el filósofo Julián Marías, discípulo de José Ortega y Gasset y experto conocedor, como no podía ser de otra manera, de las relaciones entre el sujeto y sus circunstancias. En su artículo titulado "Ramón y la realidad", llegó a afirmar que "esta pasión por la realidad ha salvado a Ramón de ser un realista" (Marías, 1957: 2) —al estilo decimonónico, se entiende-, puesto que su tratamiento literario de la realidad se caracteriza por ir más allá de lo evidente y lo superficial, habitualmente, sin embargo, relacionado con lo falaz, en busca de lo oculto y lo profundo, frecuentemente, por el contrario, vinculado a lo veraz. Tal y como explica Domingo Ródenas de Moya (2003: 36), "lo invisible, lo marginado, lo subconsciente, lo despreciado, lo fantaseado o soñado, cualesquiera regiones de la cara en sombra del mundo debían ser hozados, gozados y restituidos. La literatura de Ramón está movida por el desencubrimiento de la realidad, que a menudo desemboca en el descubrimiento de otra realidad".

Ese “otro realismo”, al que aludía Ioana Zlotescu, a través del cual el madrileño indagaría en esta "otra realidad", a la que, a su vez, hace referencia Ródenas de Moya, se revelaría en los microrrelatos fantásticos de Gómez de la Serna, entre ellos los que compila en la antología Disparates y otros caprichos Luis López Molina (2005: 14-17), quien los divide en dos tipos: los de influencia postsimbolista y modernista y los

la realidad con la de los personajes: sabemos que un texto es fantástico por su relación (conflictiva) con la realidad empírica. Porque el objetivo fundamental de todo relato fantástico es plantear la posibilidad de una quiebra de esa realidad empírica. Es por eso que va más allá del tipo de lectura que genera una narración realista o un relato maravilloso, donde al no plantearse transgresión alguna (el mundo y los sucesos narrados en el texto realista son 'normales', cotidianos, y el texto maravilloso se desarrolla en un mundo autónomo, sin contacto con el real) nuestra recepción, podríamos decirlo así, se automatiza, no necesita ese continuo entrar y salir del texto para comprender lo que está sucediendo y, sobre todo, lo que ese texto pretende" (Roas, 2001: 26). 
basados en el psicologismo propio de algunos movimientos de vanguardia. Dentro del primer grupo estarían aquellos que se corresponden con "los personajes de alto rango (emperadores, reyes o príncipes) caprichosos y despóticos; los motivos nocturnos y lunares; los mitológicos; las transformaciones prodigiosas; los seres irreales, invisibles, fantasmagóricos; las encarnaciones de la muerte; las mujeres etéreas e inasibles (con algo de becqueriano)". Ejemplos serían: "La barca que se va sola" (en Greguerías, 1917), “Las lentas carretas" (en Libro nuevo, 1920), "En la embajada de Egipto", "La cabellera de la sombra" (en "Otras fantasmagorías", Los muertos, las muertas y otras fantasmagorías, 1935), "El emperador destronado", “La dríada", "Revelación del humo" o "Verdadera falsa muerte de Calígula" (en Caprichos, 1956). Los microrrelatos fantásticos del segundo grupo, en cambio, podrían relacionarse temáticamente con "las acciones extravagantes y descabelladas; las curaciones más de la mente que del cuerpo; los sueños que invaden la realidad; la amplificación o la hipérbole de hechos de la vida corriente hasta trasladarlos a la irrealidad". Ejemplos serían: "El tirón”, “La nueva marca de automóviles" (en Disparates, 1921), "El hombre nocturno del sombrero de copa" (en Gollerías, 1926), “Dónde se fue el pájaro”, “El espejo acuarizado”, “El lago de gasa", "Récord de viajero de avión" o "Sueño del violinista" (en Caprichos, 1956).

De todos estos temas y motivos tratados por Gómez de la Serna en sus microrrelatos fantásticos destacaremos aquí, no obstante, las encarnaciones de la muerte. La lectura de aquellos microrrelatos en los que los vivos y los muertos conviven nos permitirá ver expuesto y entender mejor todo lo que hasta ahora hemos dicho en torno a las causas, los modos y los propósitos del madrileño al emplear la fantasía. Así lo expresa César Nicolás (1984: 294-295) al comentar Los muertos, las muertas y otras fantasmagorías, el que es, quizá, el más representativo de los libros del madrileño en este sentido:

Con Los muertos y las muertas Gómez de la Serna entra a saco en el tema central que subyace en su obra. Es la monografía donde vivos y muertos se confunden; la inmensa y fantasmagórica crónica del más allá. La muerte, de puro vivaz y concreta, de puro cotidiana, se torna liberadora y saludable. Percibimos a los muertos como algo familiar, entrañable. A la inversa: la vida cobra una dimensión irreal, insegura, fantasmagórica [...]. El humorismo trascendente y la paradoja son las claves de una obra que, llevándonos a una extraña forma de conocimiento (por contigüidad y analogía) deshace al tiempo multitud de tópicos abstractos e invita a percibir los fenómenos desconocidos de una forma ambigua, fehaciente e ingenua [...]. Ese vitalismo de la muerte actúa como fuente oculta de su creación, hasta generar la ruptura, la dispersión y la innovación de lo greguerístico.

Pongamos como ejemplo de ello el microrrelato titulado "En la embajada de Egipto", cuya historia se basa en la asistencia de una momia egipcia a una recepción en la embajada de su país:

\section{EN LA EMBAJADA DE EGIPTO}

En la recepción dada por el embajador de Egipto se presentó a última hora una dama que parecía vestir a la moda actual, esbelta, ceñida de sedas, con el peinado apretado al óvalo del rostro.

Nadie sabía quién pudiese ser la gallarda dama de porte tan distinguido, y solo cuando se fue, al ver la salida de baile que los criados echaron sobre sus hombros, y que era un ropaje lleno 
de jeroglíficos, se pudo comprender que era una momia egipcia que había asistido con perfecto derecho a la recepción de la embajada de su país 4 .

El mismo César Nicolás habló de "lo fantástico nuevo en Ramón Gómez de la Serna" al comprender que eran varias las innovaciones que, con respecto a las obras de otros autores de literatura fantástica, se incorporaban en sus relatos. Estas novedades tanto de enfoque como de lenguaje las asocia el investigador al surgimiento de 'lo insólito' como una nueva modalidad de lo fantástico durante el periodo de las vanguardias: "Por el carácter mismo de su ruptura, el autor se lanza a la recuperación de lo fantástico en sus más diversas formas. Pero no a la manera romántica o decimonónica. [...] Nace así la modalidad de lo insólito: la realidad más trivial, familiar y cotidiana, es contemplada desde otro ángulo, y esa percepción nos llena de estupor, de incertidumbre, de extrañamiento" (Nicolás, 1984: 296). Al margen del debate sobre si lo fantástico y lo insólito son una misma cosa o lo segundo es variante de lo primero ${ }^{5}$, nos parece especialmente interesante la conexión que establece César Nicolás entre el carácter transgresor de Gómez de la Serna y su cultivo de la fantasía. Según este, "la percepción y el lenguaje de lo insólito se convierte en un serio instrumento de crítica, de disolución del orden de lo real imperante. Al propio tiempo, nos invitan al conocimiento de otra realidad, una realidad lateral que, equidistante de lo real y de lo imaginario, emerge para manifestar lo indecible" (1984: 296).

Así pues, el tratamiento de la fantasía, además de estar relacionado con una determinada manera de observar el mundo, casaba perfectamente con el espíritu rupturista y renovador del escritor madrileño y su afán de subvertir normas y valores culturales y literarios impuestos por la tradición ${ }^{7}$. Ciertamente, como bien explica Rosie

\footnotetext{
${ }^{4}$ Cito por Disparates y otros caprichos, ed. cit., p. 193.

${ }^{5}$ La discusión puede remontarse a los postulados de Tzvetan Todorov contenidos en Introduction à la littérature fantastique (1970), donde este distinguía tres subgéneros dentro de la literatura fantástica: lo fantástico puro, lo extraño y lo maravilloso, además de otras dos subvariantes de transición: lo fantástico-extraño y lo fantástico-maravilloso. Se basó para ello en la vacilación que provoca en los personajes -incluyendo al narrador- y en el lector, o a veces solamente en este último, la presencia de los fenómenos sobrenaturales en un texto literario y, en consecuencia, en el tipo de explicación que aquellos le den o no a dichos fenómenos, pues son ellos quienes "deben decidir si lo que perciben proviene o no de la 'realidad', tal como ésta existe para la opinión común" (Todorov, 2001: 63). Entre los críticos seguidores de estas ideas de Todorov se encuentra Ana González Salvador, autora de ensayos como Continuidad de lo fantástico. Por una teoría de la literatura insólita (1980) o "De lo fantástico y de la literatura fantástica" (1984), en los que distingue entre la literatura fantástica tradicional y lo insólito como derivación de lo fantástico a partir de las vanguardias históricas.
}

${ }^{6}$ Fue el propio Gómez de la Serna (1962a: 7) quien en su "Prólogo a las novelas de la nebulosa", en El hombre perdido (1947), habló de esta "realidad lateral": "Hay una realidad que no es surrealidad ni realidad subreal, sino una realidad lateral. [...] El dominio del mundo, entre lo que vivimos en último término, es lo irreal porque todo lo real, por muerte, por consunción o solo por el paso del tiempo de ayer a mañana, resulta fatalmente irreal".

${ }^{7}$ Con respecto al carácter transgresor y crítico de Gómez de la Serna al que aludimos en este trabajo, cabe decir que debe entenderse en conexión con su primera etapa creativa, por un lado, y con el ámbito cultural y artístico, por otro. Es decir, que debiera distinguirse, en primer lugar, entre el Gómez de la Serna anterior a la época de su autoexilio y el posterior a esa fecha, y, en segundo lugar, entre los planteamientos del escritor puramente estéticos y literarios y aquellas otras que podemos definir como sus ideas políticas. Es el Gómez de la Serna de la primera época, artista de vanguardia, al que nos referimos aquí como rupturista y renovador. A otro tipo de valoraciones se presta el Gómez de la Serna que "co- 
Jackson (2001: 145-146), "en un nivel puramente temático, la literatura fantástica no es necesariamente subversiva. Afirmar que la fantasía es transgresora por definición sería adoptar una posición demasiado simplista y errónea", pues son muchos los casos en los que se ha empleado lo fantástico "para servir, antes que para subvertir, a la ideología dominante". Pero no menos verdad es que, en general, como defiende igualmente esta misma autora (2001: 148), "gracias a la utilización de algunas teorías de Freud y Lacan ha sido posible señalar que lo fantástico tiene una función subversiva en su intento de presentar un reverso de la formación cultural del sujeto. [...] El área imaginaria que se da a entender en la literatura fantástica sugiere todo lo que es otro, todo lo que está ausente de lo simbólico, fuera del discurso racional". De esto último parecía ser consciente Gómez de la Serna, como demuestran algunos de sus microrrelatos fantásticos, donde la existencia de este "reverso" o "área imaginaria" es tratado como motivo literario en sí mismo. De este modo, por ejemplo, "la apreciación de esa otra zona de lo real [lo siniestro, asimilado aquí a la oscuridad], es lo que precisamente lleva al suicidio a 'El que veía en la oscuridad' “ (Rivas, 2009: 152), título del microrrelato perteneciente a Disparates (1921) que reproduzco a continuación:

\section{EL QUE VEÍA EN LA OBSCURIDAD}

Aquel joven veía en la obscuridad porque le había mordido un gato, siendo niño, en el centro más nervioso del ser, en el codo.

Primero se creyó que aquello sería una ventaja para él; pero poco a poco fue volviéndose un misántropo.

Por ver en la obscuridad había visto antes de tiempo la verdad de la vida, la escena que la resume por entero.

Por ver en la obscuridad había visto a los seres a quienes tenía más respeto aprovecharse de la obscuridad.

Por ver en la obscuridad había visto en los túneles cómo las mujeres pálidas y de una hipocresía perfecta se dejaban coger la mano en la obscuridad, mientras los demás, desconfiando unos de otros, se echaban mano a la cartera.

Por ver en la obscuridad al entrar en los sótanos o en las profundas minas vio a los animales genuinos de la obscuridad con su cara más fea que la de nadie.

Por ver en la obscuridad vio su mismo gesto en el espejo, gesto mortal, que sin ver en la obscuridad no habría visto nunca y no le habría dejado tan desengañado.

Por ver en la obscuridad vio el gesto de hastío de las mujeres, hasta en las que dormían a su lado, y a las que no decía que veía en la obscuridad por no asustarlas.

Por ver en la obscuridad ha comprendido lo cochina que es la humanidad, que aprovecha la obscuridad para andarse en las narices.

Por ver en la obscuridad se tuvo que suicidar'.

laboró con frecuencia, tras la guerra, en los periódicos españoles, donde sus adhesiones a Franco y al franquismo fueron frecuentes: preparaba su desembarco de nuevo en España. Sus cartas de entonces a las jerarquías son tristes y rebajantes. Para el meritoriaje ni siquiera reparó en infames automutilaciones. [...] Llegó en 1949, le recibió el alcalde de Madrid, la peña superviviente de Pombo y el ¡Generalísimo!, pero nadie le aseguró la subsistencia, de manera que Ramón tuvo que volverse de nuevo a Buenos Aires [...] a sufrir lo suyo y allí murió oyendo llamarse genio en todos los periódicos de habla hispana. O sea, murió pobre: es decir, medio olvidado. [...] Su fervor franquista no le libró tampoco de la vigilancia y los informes de los servicios secretos españoles, los cuales, siempre tan perspicaces, le suponían rico en Latinoamérica, merced a 'posibles manejos masónicos', a sus publicaciones o a su matrimonio con una judía, y calificaban 'su conducta moral' de 'pésima, ya que tuvo relaciones ilícitas con varias mujeres'. Sus restos volvieron a Madrid, fueron recibidos con banda de música por el alcalde y archivados en consabida Sacramental, Sección Hombres Ilustres, junto a Fernando Villaespesa, Larra y otros, etcétera" (Trapiello, 2010: 545-546).

${ }^{8}$ Cito por Disparates y otros caprichos, ed. cit., pp. 124-125. 
Como podemos comprobar, gracias tanto a este microrrelato como a "En la embajada de Egipto", anteriormente reproducido, es muy estrecha la relación entre lo fantástico y lo humorístico, y, aunque es especialmente perceptible en autores como Gómez de la Serna' ${ }^{9}$, hablamos de un vínculo que ha sido habitual en la literatura, tal y como ha estudiado, entre otros, Georges Desmeules (1998: 66), quien incidió en la idea de que "la clase de interacción entre un protagonista y lo sobrenatural condiciona directamente la probabilidad de la actualización de este potencial humorístico". Por una parte, ambas corrientes son representativas de la inclinación al inconformismo a la que hemos hecho referencia, y, por otra parte, son, como ha explicado Irene AndresSuárez (2010: 79), dos de las tres "estrategias para reducir el microrrelato a su mínima expresión" - la otra estrategia es la intertextualidad, temática y formal. Siguiendo la propuesta de esta investigadora, lo que en última instancia se produciría es una perfecta conexión estética entre los valores pragmáticos de la fantasía (fundamentalmente su propósito de suscitar en el lector sensaciones como la inquietud, la incertidumbre, el desconcierto o la ambigüedad) y los rasgos estructurales del microrrelato (la narratividad, la concisión, la literariedad y la ficcionalidad), condicionados ambos aspectos por el ineludible uso de la elipsis.

Lo fantástico, por sus características intrínsecas -la ambigüedad; la indeterminación temática y lingüística; y la omisión de una buena parte de lo que sucede, lo que supone una exacerbación de la elipsis-, se convierte en el instrumento ideal para satisfacer una de las máximas aspiraciones de los escritores de microrrelatos: reducir al máximo la extensión del texto. Ello es más que suficiente, a mi modo de ver, para explicar la hegemonía de microrrelatos fantásticos en la literatura hispánica actual (Andres-Suárez, 2010: 120).

En torno a las relaciones entre la elipsis y la literatura fantástica, cabe destacar, no obstante, algunos trabajos anteriores como los de Rosalba Campra, entre ellos el ensayo titulado "Los silencios del texto en la literatura fantástica". Campra parte de la base de que el nivel de participación de los receptores en un acto comunicativo no es siempre el mismo, pues se ve obligado a incrementarse cuando, por ejemplo, dicha comunicación se lleva a cabo a través de un texto escrito y no oral, cuando este texto escrito, además, es ficcional y, por último, cuando este pertenece a la corriente fantástica de creación literaria. Ello se debe a que aumenta en cada caso la cantidad de información omitida, es decir, que se hace cada vez más intenso el empleo de la elipsis.

Éste es el tipo de silencio que encontramos en el cuento fantástico: un silencio cuya naturaleza y función consisten precisamente en no poder ser llenado. El sistema prevé la interrupción del proceso comunicativo como condición de su existencia: el silencio en la trama del discurso sugiere la presencia de vacíos en la trama de la realidad. [...]

Éste es un proceso que en la narrativa, por lo general, tiene la función de significar la relevancia de lo dicho y la prescindibilidad de lo omitido. En lo fantástico, en cambio, el silencio dibuja espacios de zozobra: lo no dicho es precisamente lo indispensable para la reconstrucción de los acontecimientos (Campra, 1991: 52).

Ejemplo de esta concisión narrativa basada en el recurso de elipsis podría ser el microrrelato fantástico "Las lentas carretas" (perteneciente a Libro nuevo, 1920), de

\footnotetext{
${ }_{9}^{9}$ Conviene leer al respecto el capítulo "Efectos: distanciamiento y humorismo" de la tesis doctoral de Antonio Rivas (2009: 164-168).
} 
tan sólo sesenta y cuatro palabras contando el título y en el que lo omitido parece ser, precisamente, lo que da entidad a la historia narrada:

\section{LAS LENTAS CARRETAS}

En un viaje por Oriente me encontré un carreta pesada, solemne, con el paso de elefante y que llevaba la más pesada, pero las más perenne piedra del mundo para el famoso templo de Salomón, por encargo de Salomón... Unos miles de años llevaba de camino el carro pesado y lento, camino de Jerusalén... Sus ruedas cantaban un canto del pasado ${ }^{10}$.

Como hemos visto, la fantasía existente en muchos de los microrrelatos del escritor madrileño es el resultado de un proceso condicionado, básicamente, por los tres aspectos estudiados hasta aquí: su nueva forma de observar la realidad sin la lente de la mímesis, su espíritu rupturista acorde con los nuevos movimientos de vanguardia de las primeras décadas del siglo XX y su propósito de atomizar la literatura, en general, y sus relatos, en particular. Hasta ahora, siempre se ha situado a sus célebres greguerías como manifestaciones de estos tres factores, pero, como hemos podido comprobar, también lo son sus microrrelatos fantásticos ${ }^{11}$, ejemplos todos ellos de la inagotable creatividad literaria de Ramón Gómez de la Serna.

\section{BIBLIOGRAFÍA}

Andres-Suárez, I. (2010): El microrrelato español. Una estética de la elipsis, Palencia, Menoscuarto.

Desmeules, G. (1998): “Literatura fantástica y espectro del humor", en A. Risco et alii (eds.) (1998): El relato fantástico. Historia y sistema, Salamanca, Colegio de España: 43-66.

Campra, R. (1991): “Los silencios del texto en la literatura fantástica”, en E. Morillas Ventura (ed.): El relato fantástico en España e Hispanoamérica, Madrid, Siruela: 4973.

Gómez de la Serna, R. (1923): “El monóculo sin cristal”, Nuevo Mundo (14- 12-1923), s. pp.

Gómez de la Serna, R. (1928): “El orador", http://www.youtube.com/user/ elaguilaediciones (Consultado en septiembre de 2014).

\footnotetext{
${ }^{10}$ Cito por Disparates y otros caprichos, ed. cit., p. 115.

${ }^{11}$ Ya en la primera edición de su libro Greguerías, de 1917, estas composiciones consideradas un género independiente, por unos, o un subgénero del aforismo, por otros, convivían con los microrrelatos, denominados allí por el madrileño 'caprichos' y agrupados mayoritariamente en dos capítulos: “Intermedio I. Caprichos" e "Intermedio VIII. Más caprichos". No obstante, pese a la fecha de esta primera edición, Gómez de la Serna (1962b: 13) afirmaba haber comenzado a componer greguerías varios años antes: "Desde 1910 - hace cuarenta y cinco años- me dedico a la Greguería, que nació aquel día de escepticismo y cansancio en que cogí todos los ingredientes de mi laboratorio, frasco por frasco, y los mezclé, surgiendo de su precipitado, depuración y disolución racional, la Greguería".
} 
Gómez de la Serna, R. (1962a): "Prólogo a las novelas de la nebulosa”, en El hombre perdido, Madrid, Espasa-Calpe: 7-17.

Gómez de la Serna, R. (1962b): “Prólogo”, en Total de greguerías, Madrid, Aguilar: 1380.

González Salvador, A. (1980): Continuidad de lo fantástico. Por una teoría de la literatura insólita, Barcelona, El Punto de Vista.

González Salvador, A. (1984): “De lo fantástico y de la literatura fantástica”, Anuario de Estudios Filológicos, 7, 208-226.

Gubern, R. (1997): Proyector de luna. La generación del 27 y el cine, Barcelona, Anagrama. Jackson, R. (2001): “Lo 'oculto' de la cultura", en D. Roas (ed.) (2001): Teorías de lo fantástico, Madrid, Arco: 141-152.

López Molina, L. (2005): “Introducción”, en R. Gómez de la Serna (2005): Disparates y otros caprichos, Palencia, Menoscuarto: 7-38.

Marías, J. (1957): “Ramón y la realidad”, Ínsula, 123, 2 y 8.

Nicolás, C. (1984): “Lo fantástico nuevo en Ramón Gómez de la Serna", Anuario de Estudios Filológicos, 7, 281-297.

Rivas, A. (2009): La narrativa breve de Ramón Gómez de la Serna (tesis doctoral inédita), Irene Andres-Suárez (dir.), Universidad de Neuchâtel, Suiza.

Roas, D. (2001): “La amenaza de lo fantástico", en David Roas (ed.) (2001): Teorías de lo fantástico, Madrid, Arco: 7-46.

Ródenas de Moya, D. (2003): “Ramón en la era del vacío”, Quimera, 235, 33-37.

Todorov, T. (2001): “Lo extraño y lo maravilloso”, en David Roas (ed.) (2001): Teorías de lo fantástico, Madrid, Arco: 65-81.

Trapiello, A. (2010): Las armas y las letras. Literatura y Guerra Civil (1936-1939), Barcelona, Destino.

Zlotescu, I. (1997): “Preámbulo al espacio literario del 'Ramonismo' “, en R. Gómez de la Serna (1997): Obras completas III: Ramonismo I, Barcelona, Galaxia Gutenberg: 13-33. 